\title{
A EDUCAÇÃO PERMANENTE NA FORMAÇÃO CONTÍNUA DOS PROFISSIONAIS DE ENFERMAGEM
}

\author{
Rosa Gomes dos Santos Ferreira \\ Mestre em Enfermagem - Escola de Enfermagem Anna Nery \\ Enfermeira Intensivista / HMMC \\ $\triangle$ rosaipub@gmail.com
}

\begin{abstract}
Resumo:
A formação é contínua e deve estar presente no cotidiano de trabalho e nesse contexto, emerge a educação permanente, como pacto e aproximação teórico-prática. Estes apontamentos nos dirigem ao objeto deste estudo: A educação permanente no atendimento à formação contínua e seus contrapontos e intersecções à educação em serviço e continuada. Nossos objetivos são o de descrever as práticas educativas em saúde, para os profissionais de enfermagem, enfatizando a educação permanente e analisar os contrapontos e intersecções à efetividade da assistência, mediante a prática de educação permanente. Estudo qualitativo, descritivo, tipo revisão bibliográfica. O estudo aponta que a educação permanente insurge como ferramenta capaz de despertar desejo, no trabalhador, em discutir e refletir acerca do processo de trabalho. No entanto, todas as práticas educativas, tal como a educação continuada e não apenas a educação permanente, tem valor e relevância no campo do trabalho, quando o eixo central é o trabalhador.
\end{abstract}

Palavras-chave: Enfermagem; Ensino; Educação; Educação permanente.

\section{PERMANENT EDUCATION IN-SERVICE TRAINING OF NURSING PROFESSIONALS}

\begin{abstract}
:
Training is ongoing and must be present in daily work and in this context, lifelong learning emerges as agreement and theoretical-practical approach. These notes direct us to the object of this study: Lifelong learning in attendance to continuing training and their counterparts at intersections and in-service education and continuing. Our goals are to describe the educational practices in health, nursing professionals, emphasizing lifelong learning and analyze the intersections and counterpoints to the effectiveness of assistance by the practice of lifelong learning. Qualitative, descriptive, literature review. The study shows that continuing education protests as a tool capable of awakening desire, the worker, to discuss and reflect on the work process. However, all educational practices, such as continuing education and lifelong learning not only has value and relevance in the field of work, when the central axis is the worker.
\end{abstract}

Keywords: Nursing; Teaching; Education; Permanent education. 


\section{EDUCACIÓN PERMANENTE EN SERVICIO DE FORMACIÓN DE PROFESIONALES DE ENFERMERÍA}

\section{Resumen:}

La capacitación es continua y debe estar presente en el trabajo diario y en este contexto, el aprendizaje permanente surge como acuerdo y enfoque teórico-práctico. Estas notas nos dirigen al objeto de este estudio: El aprendizaje permanente en la asistencia a la formación continua y sus contrapartes en las intersecciones y en el servicio de educación y de continuar. Nuestros objetivos son describir las prácticas educativas en salud, profesionales de enfermería, haciendo hincapié en el aprendizaje permanente y analizar las intersecciones y contrapuntos a la eficacia de la asistencia por la práctica de la educación permanente. Cualitativo, descriptivo y revisión bibliográfica. El estudio muestra que continuas protestas de educación como una herramienta capaz de despertar el deseo, el trabajador, para discutir y reflexionar sobre el proceso de trabajo. Sin embargo, todas las prácticas educativas, tales como la educación continua y el aprendizaje permanente no sólo tiene valor y relevancia en el campo de trabajo, cuando el eje central es el trabajador.

Palabras clave: Enfermería; Enseñanza; Educación; Educación permanente.

\section{INTRODUÇÃO}

A questão da educação para profissionais de saúde inseridos nos serviços ou no ensino de graduação evoluiu, transformando-se e sendo acrescida de subsídios suscitados pela dinâmica do setor saúde, de acordo com o momento sócio-econômico-político vivenciado no país.

De acordo com Silva e Furtado (2015, p. 306), a educação permanente em saúde emerge neste contexto, preocupada com as articulações entre as necessidades de aprendizagem e as do trabalho, permitindo assim, a análise e reflexão crítica dos processos de trabalho e formação.

O desenvolvimento é um processo continuado e no conjunto da prática profissional, as aptidões assistenciais, gerenciais, educativas e investigativas, descritas como bases fundamentais ao desempenho do enfermeiro, marcha através da renovação do aprendizado, como o disposto pelos projetos pedagógicos dos cursos de graduação em enfermagem.

Conforme Geib et al., (2007, p.218), o ensino superior foi desenvolvido nas escolas livres, sob a única responsabilidade do mestre, que firmava contrato com seus ouvintes e este pensamento permeou a formação e a aprendizagem no cenário do trabalho em ato, sendo secundária, a demanda de conhecimento e reflexão, por parte das equipes. 
Este aspecto formativo assume novas estações a serem contempladas, o que é fomentado pelas Diretrizes Curriculares Nacionais dos Cursos de Graduação em Enfermagem $^{1}$, que problematizam e promovem a apreciação e ajustamento dos projetos políticos pedagógicos das instituições de ensino, na finalidade de atender novas perspectivas que preveem a sustentação de profissionais capazes de trabalhar dentro da perspectiva da multidisciplinaridade, não especificamente para o agravo em saúde, mas dirigido às demandas sociais.

Corroborando Bezerra (2003, p.23), apreendemos que "a organização ou pessoa pode se considerar atualizada, apenas momentaneamente", o que torna imprescindível o aperfeiçoamento das competências, da graduação à vida profissional destes indivíduos.

E sob este aspecto, as práticas educativas se apresentam no ambiente de trabalho de enfermagem, a fim de atender aos interesses da capacitação e aprimoramento contínuos, com vista à assistência qualificada.

Na graduação ou na formação técnica em enfermagem, cabe ressaltar, que na esfera dos direitos e deveres do exercício profissional, nos é transmitido o conceito de que compete ao profissional, o direito e a responsabilidade pela qualificação e capacitação no cotidiano de seu desenvolvimento (COFEN, 2007).

O grupo de enfermagem é aquele que se emprega da permanência, da subjetividade, da aproximação, não só apenas angariando elementos inerentes à competência técnico-cientifica para desenvolvimento do cuidado.

Muitos destes aspectos podem ser considerados e desenvolvidos, assim como o aporte teórico, dentro de espaços e de práticas que permitam no ambiente do trabalho, a troca de saberes, através do processo ininterrupto de ensinar e de aprender.

O Ministério da Saúde, a contar de 2004, através da Política Nacional de Educação Permanente, implantada em 2007, abarca e concentra esforços, em uma proposta de ação voltada aos processos formativos e das práticas pedagógicas em saúde, conforme ressalta Oliveira et al. (2011, p. 48).

A Educação Permanente torna-se respeitável no desenvolvimento profissional, na 
valorização do processo de trabalho, compartilhamento e reflexão coletiva da equipe, qualificando-os pessoalmente, bem como o serviço prestado (PIAZZA, 2015, p.53).

Isto favorece o processo de formação de profissionais mais conscientes de suas responsabilidades sociais, conforme ressalta Fernandes (2004), o que configura uma nova interpretação de assistência de enfermagem e de prática educativa nos ambientes social e de trabalho.

Entretanto o enfrentamento e busca solitária por capacitação contínua, apenas por parte do trabalhador, não atinge os pressupostos assinalados anteriormente, cabendo-nos discutir a interconexão do ensino-aprendizagem, sob o aspecto da comunhão de responsabilidades em oferecer e desenvolver as práticas educativas, onde trabalhadores, gestores dos serviços de saúde e coordenadores dos programas de educação no trabalho, confluam seus interesses, para o alcance do objetivo comum.

Para Gonçalves (2005, p.21), o desafio para os gestores das organizações é transformar o trabalho em fonte de prazer para seus colaboradores e acreditamos que oferecer possibilidades de crescimento como cidadão e como profissional, através destas práticas, compõe ações que despertam a motivação, resgatando a significação do trabalho para o profissional de enfermagem.

Neste aspecto, surgem às práticas educativas no cotidiano de enfermagem, intencionadas a desenvolver táticas capazes de instigar as pessoas na busca pelo aprendizado, como assinalamos a seguir:

Há que se acreditar no ser humano, apostar na sua capacidade crítica e inovadora, saindo do modelo de punições e recompensas proposto pela maioria dos modelos administrativos que contribuiu apenas para a reprodução nas organizações da passividade e da submissão. A busca pelo prazer no trabalho exige essa mudança radical de paradigma, impõe a necessidade de proporcionar espaço para o diálogo e participação do trabalhador, a busca contínua de facilitar o processo de desenvolvimento cognitivo, transformando a organização em um ambiente de aprendizagem. (GONÇALVES, 2005, p. 22)

A partir da evolução contextual e objetiva dos processos educativos em serviço, derivaram diferentes conceitos, que são empregados, em determinados momentos, como sinônimos e, em outros, como percepções distintas: educação em serviço, educação continuada e educação permanente. 
Estes apontamentos nos dirigem ao objeto deste estudo: "A educação permanente no atendimento à formação contínua e seus contrapontos e intersecções à educação em serviço e continuada".

Para atender ao objeto de estudo foram elaborados como objetivos:

- Descrever as práticas educativas em saúde, destacando a educação permanente;

- Analisar os contrapontos e intersecções à efetividade da assistência, mediante a prática de educação permanente.

Como justificativa ao desenvolvimento desta temática está em ocasionar um movimento crítico e reflexivo, capaz de despertar a problemática do desenvolvimento e implantação da educação permanente no campo da formação contínua em saúde, como elemento transformador da assistência de enfermagem.

\section{METODOLOGIA}

Adotamos a abordagem metodológica qualitativa por trabalhar, segundo Minayo (1996) com valores, crenças, representações, hábitos, universo de significados, motivos, aspirações atitudes e opiniões, e por ser um tipo de busca interpretativo-formativa, que almeja a compreensão do tema elencado, beneficiando o processo de descobrimento, através de análise, síntese de idéias e conceitos, com envolvimento de aspectos emocionais e contextuais.

Para transformar comportamentos segundo Iervolino (2001), é imprescindível que se apreenda o contexto no qual sobrevêm os significados e a importância a eles atribuída pelos seus agentes e nesse sentido, a discussão pode servir como formato de aproximação e envolvimento do pesquisador com os leitores, permitindo a edificação grupal de idéias, conceitos, opiniões e propostas para mudanças de atitudes.

Atrelado a este aspecto, a revisão de bibliografia fundamental e legislação que permeia a questão da educação permanente e suas nuances, foi de extrema relevância à elaboração destas reflexões. 


\section{RESULTADOS}

A partir do sugerido metodologicamente, inferimos que a implantação e desenvolvimento de processos educativos para os profissionais de enfermagem, permeiam as necessidades dos serviços de saúde, dada a necessidade de adequação dos profissionais, para atuar nestes, visto que a formação baseada em currículos voltados para o modelo biomédico, hospitalocêntrico, centrado na doença, não foi capaz deste atendimento.

Uma das estratégias empregadas como forma de promover as necessárias mudanças, tem acontecido por meio dos processos educativos, visando ao desenvolvimento dos profissionais que operam o trabalho nos serviços de saúde.

A partir de 1980, a Educação Permanente em Saúde é apresentada como prioridade junto à Organização Panamericana de Saúde e à Organização Mundial da Saúde (OPAS/OMS), conforme apontam Ferraz et al., (2012).

Esta prática educativa propõe a reestruturação dos serviços, a partir do cotidiano de trabalho, tendo o profissional como sujeito, no centro do processo de ensino aprendizagem (RIBEIRO e MOTTA, 1996).

Entretanto, ainda contamos com capacitações realizadas estão relacionadas à intento de apoiar a implantação das principais estratégias dos programas verticais, com ações prescritivas, cabendo aos trabalhadores reproduzi-las mecanicamente, sem ao menos refletirem se têm pertinência com o contexto e a realidade local (DAVINI, 1994).

Certamente, este perfil não é mais o esperado pelo profissional de enfermagem, nem pelo gestor do serviço de saúde, no que tange ao desenvolvimento das atividades de atualização e capacitação no cotidiano do trabalhador.

Os profissionais que cumprem os processos educativos são os de nível superior ou gerentes dos serviços, sugerindo que teriam facilidade de apreender e repassar para os profissionais, os conteúdos necessários à capacitação. Entretanto, pensar deste modo hierárquico e vertical, acomodando todo o conhecimento nas mãos de um profissional que "deteria o saber", faz permanecer a concepção fragmentada do processo, onde os trabalhadores são separados e não possuem direito à escolha e reflexão.

As atividades cognitivas relacionadas com o elaborar, criar, planejar, programar e analisar, ficam a cargo de profissionais que detêm maior escolarização. Dessa forma, os que 
executam as ações, não se sentem parte do processo de trabalho e as necessidades de capacitação, emergem das pessoas que planejam e não das que executam e que vivenciam as dificuldades do cotidiano das práticas em saúde.

Este é um grave problema que deve ser arrolado à análise do grupo que compõe este processo de ensino-aprendizagem, antes de qualquer implantação de novos conceitos ou modalidades educativas em serviço.

Apesar de se acreditar na capacidade e na importância da renovação dos conhecimentos técnico-científicos para a melhoria da qualidade da atenção em saúde, os processos educativos, em sua maioria, privilegiavam esse tipo de conhecimento, o que é contrária à recomendação da OPAS (1997) que refere que considerar e analisar os contextos dos serviços e os fatores do processo produtivo em saúde.

Para constituir processos educativos para os serviços hoje, tornou-se indispensável pensar o trabalho, a configuração dos trabalhadores inseridos no processo de trabalho e nos contextos reais de suas práticas (DAVINI, 1994), onde alocar os trabalhadores tanto no centro do processo ensino-aprendizagem, como no centro do processo de trabalho, reconhecendo-os como componente desses métodos, consiste no movimentador do aprendizado.

Os processos educativos planejados, a partir da reflexão das necessidades que emergem do cotidiano das práticas dos profissionais, devem ser avaliados com atenção, porque a maioria dos serviços não acompanhou as mudanças, não se preparou e não se atualizou de acordo com a evolução dos sistemas.

A OPAS (1997) discute que, para se agenciar projetos de capacitação eficazes, deve-se responder às necessidades educacionais com base nos problemas identificados pelos trabalhadores e gestores dos serviços, que sejam programados conjuntamente, que sejam pertinentes ao identificado e que sejam avaliados periodicamente.

Além de esses projetos serem consonantes com a política nacional e local, certificar profissionais para transformar as suas realidades é uma obra para além de um treinamento, um processo que aparece da identificação dos problemas, através da observação e da reflexão, culminando na ação transformadora, que de acordo com Freire (1983), é a premissa da educação. 


\section{A EDUCAÇÃO PERMANENTE NA FORMAÇÃO \\ CONTÍNUA DOS PROFISSIONAIS DE ENFERMAGEM}

As concepções democráticas, emancipatórias e transformadoras sustentadas pelo ideal de Paulo Freire, podem ser vislumbradas na educação permanente, a qual se utiliza das experiências cotidianas e embates, para capacitar e atualizar pessoas, alicerçada na perspectiva de educar como modo de transformar e realizar aprendizagem significativa, na valorização do trabalho como manancial de conhecimento e na articulação com e entre atenção à saúde, controle social e gestão, conforme coloca Silva (2015, p.124)

O desenvolvimento de educação permanente tem sido sugerido como metodologia e estratégia de ensino e de serviço para o pessoal dos serviços de saúde e do ensino, que está em busca de reestruturação dos sistemas de saúde (OPAS, 1997).

É entendido que os serviços de saúde são ambientes de ações contínuas de trabalho e ensino, porque comumente se vivenciam, nesses espaços, as situações-problemas, cabendo aos que trabalham discuti-las e superá-las. Portanto, são considerados ótimos espaços de ensino-aprendizagem, pois desenvolvem, nos sujeitos que os freqüentam, a reflexão, a crítica e as atitudes. Mas, para que a superação seja um processo de transformação para a melhoria da qualidade da assistência prestada à população, é consenso que os trabalhadores da saúde, identifiquem e distingam a situação-problema, para interpretar seus determinantes, sendo necessário situar e valorizar o contexto do trabalho, as inter-relações existentes, os aspectos socioeconômicos e políticos que estão em torno desses sítios.

Dentro dessa concepção, é necessário perceber a instituição quanto a sua cultura, que contém um esqueleto de poder e que realiza um trabalho, onde cada um possui seu habitus, que é o clima cultural e ideológico em que transcorre a vida do trabalho.

A mesma desvinculação do processo educativo dos contextos nos quais os profissionais estão inseridos ocorre no ensino, embora modificações ocorram gradativamente.

A formação nos cursos de graduação da área de saúde ainda é desarticulada do contexto e das necessidades do país, oferecendo à sociedade, profissionais reprodutores de conhecimento e com insuficiente envolvimento no referente à responsabilidade social na intervenção no processo saúde-doença.

A importância de formar profissionais qualificados para o trabalho está no texto da Lei de Diretrizes e Bases da Educação Nacional - LDB (BRASIL, 1996), onde se menciona que a 
educação deve preparar o aluno para a vida, tendo por escopo o seu pleno desenvolvimento, seu preparo para o exercício da cidadania e sua qualificação para o trabalho.

Construir perfil acadêmico e profissional com competências e habilidades e conteúdos contemporâneos, para atuar com qualidade e resolutividade no SUS deve ser o novo modelo orientador formativo, pautado no entendimento de que saúde é um processo de trabalho coletivo do qual resulta, como produto, a prestação de cuidados de saúde (ALMEIDA, 2003).

Adotar o trabalho como centro do ensino-aprendizagem, seja na graduação ou na capacitação profissional, antecede do diagnóstico e apreciação dos fatores acima aludidos. Isso é fundamental para que o trabalho seja norteador da qualificação, pois, caso não seja devidamente analisado, poderá se tornar desqualificador dos agentes na prática, dependendo do entendimento que os profissionais obtenham do todo.

A educação permanente passa a existir inicialmente, nos países desenvolvidos da Europa Ocidental. Na América Latina, tem sido apresentada e divulgada pela Organização Pan-Americana de Saúde - OPAS, desde a década de 80.

Para DAVINI (1994), o conceito de educação permanente em saúde busca alternativas e soluções para os problemas reais e concretos do trabalho, privilegiando o processo de trabalho como eixo central da aprendizagem e enfatizando a capacidade humana de criar conhecimento novo, a partir da discussão e análise participativas, de suas causas e das implicações que as alternativas de solução têm na busca da transformação da prática de saúde, objetivo essencial do ato educativo.

A educação permanente se sustenta no conceito de "ensino problematizador" e de "aprendizagem significativa" (interessada nas experiências anteriores e nas vivências pessoais dos alunos, desafiante do desejar aprender mais), ou seja, ensino-aprendizagem embasado na produção de conhecimentos que respondam a perguntas que pertencem ao universo de experiências e vivências de quem aprende e que gerem novas perguntas sobre o ser e o atuar no mundo.

É a escolha por novas maneiras de desempenhar atividades, com maior resolutividade, aceitação e compartilhamento entre os coletivos de trabalho, ambicionando a implicação profunda com os usuários dos sistemas de saúde, com os coletivos de formulação e 
implantação do trabalho, e um processo de desenvolvimento setorial por "encontro" com a população.

A educação permanente em saúde não expressa, portanto, uma opção didáticopedagógica, expressa uma opção político-pedagógica, amplamente debatida pela sociedade brasileira organizada em torno da temática da saúde, tendo sido aprovada na XII Conferência Nacional de Saúde e no Conselho Nacional de Saúde (CNS) como política específica no interesse do sistema de saúde nacional, o que se pode constatar por meio da Resolução CNS n. 353/2003 e da Portaria MS/GM n. 198/2004.

A educação permanente em saúde tornou-se a estratégia do SUS para a formação e o desenvolvimento de trabalhadores para a saúde, onde se afirma e se preconiza: 1) a articulação entre ensino, trabalho e cidadania; 2) a vinculação entre formação, assistência e gestão; 3) o reconhecimento de bases regionais como unidades político-territoriais onde estruturas de ensino e de serviços devem se encontrar em 'co-operação' para a formulação de estratégias para o ensino, assim como para o crescimento da gestão setorial, a qualificação da organização da atenção em linhas de cuidado, o fortalecimento do controle social e o investimento na intersetorialidade.

O eixo para formular, implantar e avaliar a 'educação permanente em saúde' deve ser o da integralidade e o da implicação com os usuários.

Para a educação permanente em saúde, não existe a educação de um ser que sabe para um ser que não sabe, o que existe, como em qualquer educação crítica e transformadora, é a troca e o intercâmbio, o estranhamento de saberes e a desacomodação com os saberes e as práticas que estejam vigentes.

A educação permanente tem assumido diferentes entendimentos no trabalho em saúde, onde a inovação tecnológica a tem colocado como necessidade de constante para acompanhar o desenvolvimento do mundo moderno.

O trabalho em saúde é concretizado pela ação dos profissionais que tem como papel principal, oferecer assistência no processo de saúde-doença do indivíduo, da comunidade nas situações de tratamento, prevenção e reabilitação. 
Nessa perspectiva, Pires (2000, p. 85) define o trabalho em saúde como essencial à vida humana, fazendo parte do setor de serviços, "é um trabalho da esfera da produção nãomaterial, que se completa no ato da sua realização".

Aponta que uma das peculiaridades desse tipo de trabalho é que seu produto não surge de forma concreta no fim do processo, não se lança uma mercadoria para ser comercializada, pois o resultado do trabalho é consumido no momento em que é produzido.

Nesse processo, a organização do trabalho em saúde tem por finalidade atender o ser humano que, em algum momento de sua vida, necessita de atenção profissional de saúde, sejam ações preventivas, curativas e ou de reabilitação.

A lógica que sustenta as ações de assistência à saúde está consubstanciada nos princípios do SUS que procura modificar a lógica da organização e a formação do trabalho em saúde com vistas a novos modelos assistenciais e de gestão.

A educação permanente vista como tática de formação e desenvolvimento dos/as profissionais da saúde propõe que os processos de qualificação abordem as necessidades de saúde das pessoas e comunidades no sentido de transformar essas práticas e a organização do trabalho (BRASIL, 2005).

Na perspectiva de compreender as concepções educativas que norteiam e influenciam o ensino da enfermagem, sintetizam-se as idéias centrais das linhas pedagógicas que desempenharam influência na estruturação da educação permanente ao longo do tempo.

Tentando conhecer como tem sido produzido o conhecimento acerca da educação permanente na enfermagem, Backes et al.(2003) realizou uma busca aos estudos publicados sobre o tema nos periódicos nacionais e internacionais nos cinco últimos anos, no sentido de identificar como vêm se estruturando as diferentes concepções teóricas e práticas da educação permanente no âmbito da enfermagem, bem como apreender as possibilidades e limites colocados em prática.

Ressaltaram os autores que a nomenclatura "educação permanente", vem sendo utilizada após o estabelecimento da "Política de Educação e Desenvolvimento para o SUS: caminhos para a educação permanente em saúde” (BRASIL, 2005), ser implantada no país. 


\section{A EDUCAÇÃO PERMANENTE NA FORMAÇÃO \\ CONTÍNUA DOS PROFISSIONAIS DE ENFERMAGEM}

Anteriormente, a educação no trabalho era apreendida como educação continuada, que quando concebida como possibilidade de favorecer o crescimento integral do/a profissional, admite a mesma concepção da educação permanente hoje defendida pelas políticas públicas.

\section{DISCUSSÃO}

O processo de produção da atenção à saúde se inicia, em linhas gerais, praticando a capacitação dos trabalhadores com o desígnio de melhorar a competência do pessoal ativo.

Entretanto, a postura protetora e interventora da capacitação em serviço, faz com que os trabalhadores não se sintam envolvidos e nem responsáveis pelas ações desenvolvidas.

Alguns dos processos educativos têm como finalidade certificar os profissionais para produzirem em quantidade as ações, não apreciando a qualidade como sendo um dos objetivos propostos.

Os processos educacionais, frente às inovações apresentadas pelo SUS, são vistos como a possibilidade de nortear a melhoria da qualidade de assistência prestada aos usuários.

A necessidade de se implantar o modelo assistencial proposto pelo SUS que é pautado na integralidade exige dos trabalhadores, atitudes, habilidades e competências que não se adquiriram durante sua formação e nem nos processos educativos realizados pelos serviços.

Os trabalhadores devem compreender que habilidades e conhecimentos específicos são necessários à sua prática, com clara percepção do processo de trabalho como um todo, onde a aprendizagem deixa de ser a obtenção de conhecimentos para o alcance de desempenho eficiente para o trabalho, sugerindo que os processos educativos em serviços sejam desenvolvidos a partir das competências necessárias ao trabalho.

Isto é o que propõe a educação permanente, pois pactua eventos do trabalho, trabalhadores e aporte teórico, com vistas à devolução de um produto social e não apenas de um atualizado colaborador. 


\section{CONSIDERAÇÕES FINAIS}

Se a formação dos profissionais de saúde, além de tecnicamente qualificada, não for envolvida com o contexto social, poderá distanciar-se da sugestão inicial que é imprescindível para o trabalho em saúde.

O projeto político pedagógico das instituições de ensino em enfermagem indica a formação contínua de indivíduos habilitados na elaboração do processo de trabalho coletivo, multidisciplinar, valorizando os saberes, na constituição de um produto refinado de atendimento centrado na causa e não da doença.

A educação permanente vem de encontro às aspirações propostas, desde a graduação, perpetuando essa perspectiva, no cotidiano do trabalho em ato, constituindo-se uma formação por competências, aconchegando o conhecimento técnico e teórico ao cenário social.

Entendemos que todas as práticas educativas, embora o destaque desta discussão, seja a educação permanente, tem valor e penetrância no campo do trabalho e não podem desvincular-se dele.

Cada modalidade conflui para o alcance de objetivos inicialmente discutidos e se utiliza de especificidade, mas há entrecorte no que tange aos elementos que subsidiam o desenvolvimento de suas estratégias: o trabalhador em saúde, sua demanda de aprendizado, o trabalho e o alcance de suas ações. Estes são alicerces de sustentação de qualquer intervenção de capacitação e qualificação dos trabalhadores em cena.

Os objetivos foram alcançados no que se refere descrever as práticas educativas em saúde, enfatizando a educação permanente; analisando os contrapontos e intersecções à educação continuada e permanente.

Esperamos poder contribuir com a discussão, abordando o assunto "educação permanente", como também promover esclarecimento referente aos aspectos sócio-históricos que emergiram e sugestionaram as terminologias: educação em serviço, continuada e permanente. 


\section{A EDUCAÇÃO PERMANENTE NA FORMAÇÃO \\ CONTÍNUA DOS PROFISSIONAIS DE ENFERMAGEM}

\section{REFERÊNCIAS BIBLIOGRÁFICAS}

ALMEIDA, M. E. B.. Educação a distância na internet: abordagens e contribuições dos ambientes digitais de aprendizagem. Educ. Pesqui., São Paulo, v. 29, n. 2, p.327-340, 2003. Disponível em: $\langle$ http://www.scielo.br/scielo.php?pid=S1517-97022003000200010\&script=sci_arttext $>$. Acesso em: 15 dez. 2015 .

BACKES, V. M. S.; SCHMIDT, S. M. S.; NIETSCHE, E. A.. Educação continuada: algumas considerações na história da educação e os reflexos na enfermagem. Texto Contexto Enfermagem, Florianópolis, v. 12, n. 1, p.80-88, 2003.

BEZERRA, A. L. Q.. O contexto da educação continuada em enfermagem. São Paulo: Martinari, 2003. 112 p.

BRASIL, MINISTÉRIO DA EDUCAÇÃO. . Lei No 9.394, de 20 de Dezembro de 1996.: Estabelece as diretrizes e bases da educação nacional. Brasília, DF, 20 dez. 1996. Disponível em: <http://www.planalto.gov.br/ccivil_03/Leis/L9394.htm>. Acesso em: 15 dez. 2015.

BRASIL. CONSELHO NACIONAL DE EDUCAÇÃO, CÂMARA DE EDUCAÇÃO SUPERIOR. Resolução CNE/CES N ${ }^{\circ}$ 3, de 7 de Novembro 2001: Institui Diretrizes Curriculares Nacionais do Curso de Graduação em Enfermagem.. Brasília, DF, Disponível em: < http://portal.mec.gov.br/cne/arquivos/pdf/CES03.pdf>. Acesso em: 15 dez. 2015.

BRASIL/Ministério da Saúde. Secretaria de Gestão do Trabalho e da Educação na Saúde. Departamento de Gestão da Educação na Saúde. A Educação Permanente Entra na Roda: pólos de educação permanente em saúde - conceitos e caminhos a percorrer. 2. ed. Brasília: Ministério da Saúde, 2005. 36 p. (Série C. Projetos, Programas e Relatórios). Disponível em: $\langle$ http://bvsms.saude.gov.br/bvs/publicacoes/educacao_permanente_entra_na roda.pdf $>$. Acesso em: 15 dez. 2015.

COFEN - CONSELHO FEDERAL DE ENFERMAGEM. Resolução $\mathbf{N}^{\circ} 311$ de 08 de Fevereiro de 2007: Aprova a reformulação do Código de Ética dos Profissionais de Enfermagem. Rio de Janeiro, 8 fev. 2007. Disponível em: 〈http://www.cofen.gov.br/resoluo-cofen-3112007 4345.html〉. Acesso em: 15 dez. 2015.

DAVINI, M. C. (Org.). Educación permanente en salud. Washington: Organización Panamericana de La Salud, 1995. 120 p. (Serie PALTEX para Ejecutores de Programas de Salud). Disponível em: < http://apps.who.int/iris/bitstream/10665/173954/1/Educacion\%20permanente\%20en\%20salud.pdf $>$. Acesso em: 15 dez. 2015.

FERNANDES, C. N. S.. Refletindo sobre o aprendizado do papel de educador no processo de formação do enfermeiro. Revista Latino-americana de Enfermagem, Ribeirão Preto, v. 12, n. 4, p.691-693, 2004. Disponível em: $\quad$ http://www.scielo.br/scielo.php?script=sci_arttext\&pid=S0104$\underline{11692004000400017 \& \operatorname{lng}=\mathrm{en} \& n r m=i s o \& t \operatorname{lng}=\mathrm{pt}>}$. Acesso em: $15 \mathrm{dez} .2015$.

FERRAZ, F.; BACKES, V. M. S.; MERCADO-MARTÍNEZ, F. J.; M. L.,PRADO. Políticas e programas de educação permanente em saúde no Brasil: revisão integrativa de literatura. Saúde \& Transformação Social, Florianópolis, $\quad$ v. $\quad 3, \quad$ n. $\quad 2, \quad$ p.113-128, 2012. Disponível em: 〈http://incubadora.periodicos.ufsc.br/index.php/saudeetransformacao/article/view/1488>. Acesso em: $15 \mathrm{dez}$. 2015 .

FREIRE, P.. Pedagogia do oprimido. 12. ed. Rio de Janeiro: Paz e Terra, 1983.

GEIB, L. T. C. et al. A tutoria acadêmica no contexto histórico da educação. Revista Brasileira de Enfermagem, Brasília, v. $60, \quad$ n. 2 , p.217-220, abr. 2007.2 Disponível em: <http://www.scielo.br/scielo.php?pid=S0034-71672007000200017\&script=sci_arttext >. Acesso em: 15 dez. 2015 . 
GONÇALVES, S.. O Trabalho e Sua Origem. In: GONÇALVES, S.. Motivação: uma trilha para o sucesso. Itapetininga: Editora FII, 2005. p. 21-22.

LERVOLINO, S. A.; PELICIONI, M. C. F.. A utilização do grupo focal como metodologia qualitativa na promoção da saúde. Revista da Escola de Enfermagem da Usp, São Paulo, v. 35, n. 2, p.115-121, 2001. Disponível em: 〈http://www.revistas.usp.br/reeusp/article/view/41220>. Acesso em: 15 dez. 2015.

MINAYO, M. C. S.. O desafio do conhecimento. 4. ed. São Paulo: Hucitec, 1996. 408 p.

OLIVEIRA, F. M. C. S. N.; FERREIRA, E. C.; RUFINO, N. A.; SANTOS, M. S. S.. Educação permanente e qualidade da assistência à saúde: aprendizagem significativa no trabalho da enfermagem. Aquichán, Bogotá, v. 11, n. 1, p.48-65, abr. 2011. Disponível em: <http://www.scielo.org.co/scielo.php?pid=S165759972011000100005\&script=sci_arttext>. Acesso em: 15 dez. 2015.

ORGANIZACIÓN PANAMERICANA DE LA SALUD/ ORGANIZACIÓN MUNDIAL DE LA SALUD. División de desarrollo de sistems y servicios de salud (HSP). Programa de desarrollo de recursos humanos (HSR). El desafio educativo de las reformas sectoriales: câmbios em la capacitación y la capacitación em salud. Buenos Aires: Organización Panamaricana de La Salud, 1997. 38 p. (Serie Desarrollo de Recursos Humanos).

PIAZZA, M.; RAMOS, B.J.; OLIVEIRA, S.N.; PRADO, M. L.; MASSAROLI, A.; ZAMPROGNA, K. M.. Educação permanente em unidades de pronto atendimento 24 horas: necessidade e contribuição à enfermagem. Journal Of Nursing And Health, Pelotas, v. 5, n. 1, p.47-54, 2015. Disponível em:

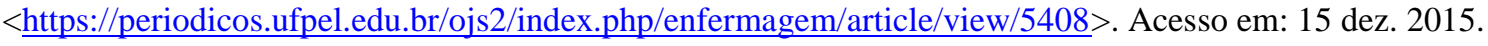

RIBEIRO, E. C. O.; MOTTA, J. I. J.. Educação permanente como estratégia na reorganização dos serviços de saúde. Divulgação em Saúde Para Debate, Londrina, v. 12, , p.39-44, 1996. Disponível em: <http://www.redeunida.org.br/producao/artigo03.asp >. Acesso em: 15 dez. 2015.

PIRES, D. Novas formas de organização do trabalho em saúde e enfermagem. Rev Baiana Enfermagem. Salvador, v.13, n.1/2, p. 83-92, 2000.

SILVA, A. A. Formação em saúde: representações de acadêmicos sobre metodologias ativas de ensino e aprendizagem. Cadernos da Fucamp. Campinas, v.14, n.21, p.120-138, 2015. Disponível em: < http://www.fucamp.edu.br/editora/index.php/cadernos/article/viewFile/607/433 >. Acesso em: 15 dez. 2015.

SILVA, L. S.; FURTADO, L. A. R.. Educação permanente em saúde e estratégia de saúde da família: Revisão integrativa. Revista Uniabeu, Berford-roxo, v. 8, n. 19, p.305-320, ago. 2015. Disponível em: <http://www.uniabeu.edu.br/publica/index.php/RU/article/view/1764/pdf_248>. Acesso em: 15 dez. 2015. 